\title{
APRENDIZAGEM SIGNIFICATIVA COMO ALICERCE PARA METODOLOGIAS ATIVAS NO ENSINO DE CIÊNCIAS: UMA INTERLOCUÇÃO EM PROL DA EDUCAÇÃO DE JOVENS E ADULTOS
}

Elizabeth Augustinho ${ }^{1}$

Valéria da Silva Vieira ${ }^{2}$

\begin{abstract}
RESUMO
O artigo apresenta reflexões sobre como a educação de jovens e adultos pode ser ressignificada, na busca de uma participação ativa do aluno, na qual ele seja protagonista e sujeito de sua aprendizagem. Destaca a importância da formação docente para atuar nessa modalidade de ensino. Trata-se de uma pesquisa bibliográfica, descritiva, elaborada com base na experiência em sala de aula e por meio de leitura de vasto material bibliográfico, que motivaram o aprofundamento do tema, priorizando autores de referência, como: Freire, Ausubel, Moran, Chassot. Além de apresentar conceitos fundamentais relacionados à aprendizagem significativa, é destacada a importância das metodologias ativas, que podem se tornar estratégias eficazes para a aprendizagem significativa em ciências na educação de jovens e adultos.
\end{abstract}

Palavras-chaves: Educação de jovens e adultos. Aprendizagem significativa. Metodologias ativas. Ensino de ciências.

\section{MEANINGFUL LEARNING AS A FOUNDATION FOR ACTIVE METHODOLOGIES IN TEACHING SCIENCES: DIALOGUING TOWARDS THE EDUCATION OF YOUTH AND ADULTS}

\begin{abstract}
The article presents reflections on how the education of young people and adults can be reframed, in the search for an active participation of the student, in which he is the protagonist and subject of his learning. It highlights the importance of teacher training to work in this type of teaching. This is a bibliographic, descriptive research, based on the experience in the classroom and through the reading of vast bibliographic material, which motivated the deepening of the theme, prioritizing reference authors, such as: Freire, Ausubel, Moran, Chassot. In addition to presenting fundamental concepts related to meaningful learning, the importance of active methodologies is highlighted, which can become effective strategies for meaningful learning in science in youth and adult education.
\end{abstract}

Keywords: Youth and adult education. Meaningful learning. Active methodologies. Science teaching.

Data da submissão 30.09.2020

Data da aprovação 02.12.2020

\section{INTRODUÇÃO}

O cenário atual é permeado por mudanças constantes, no qual os conhecimentos se tornam voláteis se não tiverem significado e utilidade para a sociedade. A pluralidade cultural, política, científica, étnica, fazem parte dessa realidade.

\footnotetext{
${ }^{1}$ Graduada em Pedagogia- UFRJ. Mestra em Ensino de Ciências - IFRJ/ Campus Nilópolis. E-mail: elizabeth.augustinho@ifrj.edu.br

${ }^{2}$ Professora Doutora do IFRJ/ Campus Nilópolis. Instituição; Instituto Federal de Educação Ciência e Tecnologia do Rio de Janeiro - IFRJ. E-mail: valeria.vieira@ifj.edu.br
} 


\begin{abstract}
Vivemos em tempos de ressignificações, de profundas mudanças, de contestações de toda ordem, de crise da ciência e da sociedade moderna. Época marcada pela transitoriedade, pela busca de novos sentidos e de novas práticas. Práticas que sejam mais próximas da contingência histórica da condição humana e que contribuam para a reconstrução do atual contexto (SILVA, 2003, p.7).
\end{abstract}

Repensar e reconstruir tal contexto é imprescindível; rever velhas ações e práticas pedagógicas que não são coerentes com um cenário que se pretende ser mais humanizado. Portanto, não cabe mais à escola a função exclusiva de transmissão de conteúdo. As novas tecnologias oportunizaram o acesso às informações pelas mais variadas fontes. Assim, se faz necessário ressignificar a educação, especialmente a educação de jovens e adultos (EJA), para que haja coerência com essa nova realidade e, consequentemente, é imprescindível um novo perfil de professor e uma concepção de aprendizagem em consonância com esse projeto. Freire (2007, p.29), ressalta que "o saber se faz através de uma superação constante. O saber superado já é uma ignorância. Todo saber humano tem em si o testemunho do novo saber que já anuncia. Todo saber traz consigo sua própria superação.” Assim, o autor nos apresenta a relativização do saber, do conhecimento.

Nesse contexto, a escola precisa reconhecer a transitoriedade das informações e o professor tem um novo papel, mais adequado a essa realidade: o de mediador da aprendizagem. Ele é aquele que cria o ambiente propício para o desenvolvimento dos alunos e para a colaboração mútua. Portanto, esse profissional precisa conhecer bem seus alunos para poder escolher metodologias adequadas ao seu público, buscando garantir a participação ativa desses, enquanto sujeitos de suas aprendizagens, bem com a construção de uma aprendizagem significativa. Uma aprendizagem que faça a diferença na vida dos alunos, que seja crítica e reflexiva, contribuindo para a construção e reconstrução permanente de cada um como cidadão e ser social.

Assim, repensar a função da escola, do professor, da aprendizagem representam desafios importantes que estão postos, principalmente quando falamos de EJA. Essa modalidade de ensino que inclui uma parcela da população marcada pela exclusão de direitos e por desigualdades sociais.

Refletir sobre como esses jovens e adultos pensam e aprendem envolve, portanto, transitar pelo menos por três campos que contribuem para a definição de seu lugar social: a condição de "não-crianças", a condição de excluídos da escola e a condição de membros de determinados grupos culturais (OLIVEIRA, 1999, p. 60).

Nesse sentido, a EJA representa uma modalidade de ensino que deve problematizar as questões do cotidiano, indo além de uma simples compensação do tempo perdido e possuir uma proposta mais abrangente, de emancipação social, participativa, cidadã, de formação política para a construção de uma educação mais inclusiva, humanizada, seguindo os ideais de Paulo Freire.

Nessa perspectiva, o Ensino de Ciências a ser implementado nessa modalidade deve priorizar questões atuais, que tenham relevância para o seu público, que problematizem o cotidiano e o modo de vida das pessoas, ou seja, pensar no Ensino de Ciências adequado à EJA, através de metodologias ativas de ensino que levem a aprendizagem significativa de seus sujeitos.

Com esse propósito, o presente artigo foi elaborado, a partir da observação prática da realidade da sala de aula e de um estudo de vasto material bibliográfico. Trata-se de uma pesquisa bibliográfica, de cunho descritivo, que se propõe a apresentar aspectos relevantes para a prática pedagógica crítica e reflexiva na EJA, buscando alinhar estudos da teoria da aprendizagem significativa como alicerce para a implementação de metodologias ativas no 
ensino de ciências, em prol de uma educação de jovens e adultos coerente com as demandas atuais da sociedade.

\title{
1 CONHECIMENTOS PARA A VIDA E A EDUCAÇÃO DE JOVENS E ADULTOS
}

Para aprender, o sujeito elabora hipóteses sobre a realidade, interage com o meio e com os outros, reconstruindo suas percepções e avançando na compreensão desta realidade. Fávero (2007, p. 45) afirma que "o conhecimento é adquirido através de um processo construtivo, no qual a aprendizagem dos sujeitos não é dada a priori e nem mesmo resulta do acúmulo de informações recebidas do meio externo." Desta maneira, realiza-se um processo dialético de elaboração e reelaboração do conhecimento, no qual os conhecimentos prévios adquiridos ao longo da vida servem como ponto de partida para novas aprendizagens. Assim, aprendemos desde que nascemos e iremos aprender até o fim da vida.

Nesse contexto, quando pensamos na EJA, as estratégias de seleção e organização dos conteúdos curriculares, bem como os critérios dessa escolha, devem considerar os conhecimentos, experiências, interesses e expectativas desses jovens e adultos, em consonância com a realidade vivenciada por eles. Souza (2011) acrescenta que:

\begin{abstract}
mais do que diagnosticar que saberes os jovens e adultos trazem [...], é preciso saber quem e quantos são, que necessidades de escolarização e de outras formações culturais demandam, que condições socioeconômicas e motivações de aprendizagem apresentam (SOUZA, 2011, p.191).
\end{abstract}

Portanto, a adequação da linguagem e de propostas curriculares diferenciadas para a EJA também merecem destaque quando falamos em metodologia adequada a este público, pois ainda se observa em sala de aula a infantilização da EJA com o uso de expressões e atitudes usadas com crianças. Oliveira (2007), destaca que expressões e atitudes, como: resolver a folhinha, fazer a continha, realizar o dever de casa são totalmente inapropriadas para jovens e adultos, reafirmando uma visão compensatória da EJA e o sentimento de não pertencimento à escola.

É preciso reconhecer que esse aluno, jovem ou adulto, retorna aos bancos escolares com uma bagagem já construída, com uma história de vida e conhecimentos acumulados que podem e devem ser valorizados pela escola.

\footnotetext{
O aluno trabalhador é concebido com um ser social que traz experiências de vida e conhecimentos acumulados. Um sujeito fazedor de história que intervém na realidade e que se constrói nas ações coletivas. Um ser integral, cujas dimensões cognitivas, físicas, emocionais, econômicas, políticas, sociais, culturais, éticas e estéticas e espirituais interagem no processo de construção do conhecimento (FÁVERO, 2007, p. 45).
}

É esse sujeito real que deve receber uma educação coerente com sua realidade, com seus interesses e objetivos; e o currículo e as práticas metodológicas da EJA devem ser selecionados e planejados de acordo com essa realidade. Souza (2011, p.191) ratifica pontuando que "cabe, também, ajustar as propostas pedagógicas às peculiaridades dos contextos locais e dos subgrupos sociais [...].” Portanto, uma educação adequada aos sujeitos da EJA.

De acordo com o Parecer CNE/CEB n ${ }^{\circ} 11 / 2000$, que trata das Diretrizes Curriculares Nacionais para a Educação de Jovens e Adultos, "a EJA necessita ser pensada como um modelo pedagógico próprio, a fim de criar situações pedagógicas e satisfazer necessidades de aprendizagem de jovens e adultos".

Assim, não cabe oferecer ao aluno da EJA uma educação aligeirada ou fragmentada; é necessário pensar em um ensino adequado à sua realidade. Porém, essa adequação não é 
sinônimo de redução nem simplificação. O aluno da EJA necessita de uma formação de qualidade na Educação Básica, integrada ao mundo do trabalho sempre que possível, respeitando suas especificidades, mas que o permita a prosseguir seus estudos na Educação Superior, se esse for o seu desejo. Portanto, a aprendizagem precisar ser significativa e os conhecimentos construídos devem servir para a melhoria da vida de seus sujeitos. Como aponta Alarcão (2003), o conhecimento tem que ser um bem comum e a aprendizagem ao longo da vida, deve ser mais que um direito, e sim, uma necessidade humana.

\section{A APRENDIZAGEM SIGNIFICATIVA}

O conceito de aprendizagem significativa apresentado nesse trabalho tem como referencial o postulado de Ausubel (2003), ao elaborar a teoria da assimilação da aprendizagem e da retenção significativas, a partir dos mecanismos de explicação dos processos psicológicos de aprendizagem e de retenção cognitivas humanas. Assim, a aprendizagem significativa ocorre quando uma nova informação se relaciona com um aspecto relevante da estrutura de conhecimento do aprendiz, produzindo novos significados. Moreira (2012, p. 5) destaca que os "aspectos relevantes da estrutura cognitiva que servem de ancoradouro para a nova informação são chamados subsunçores". Acrescenta que, à medida que o conhecimento prévio serve de base para a atribuição de significados à nova informação, ele também se modifica, ou seja, os subsunçores vão adquirindo novos significados se tornando mais diferenciados, mais estáveis. Para Ausubel,

O conhecimento é significativo por definição. É o produto significativo de um processo psicológico cognitivo (saber) que envolve a interação entre ideias logicamente (culturalmente) significativas, ideias anteriores (ancoradas) relevantes da estrutura cognitiva particular do aprendiz (ou estrutura dos conhecimentos deste) e o mecanismo mental do mesmo para aprender de forma significativa ou para adquirir e reter conhecimentos (AUSUBEL, 2003, p. vi).

O autor destaca algumas definições importantes para apreensão de sua teoria. Ele apresenta os tipos de aprendizagem por recepção significativa como sendo: aprendizagem representacional, aprendizagem conceitual e aprendizagem proposicional. A aprendizagem representacional é definida por ele como sendo aquela que se aproxima da aprendizagem por memorização, porém é significativa, pois ocorre sempre que o significado dos símbolos arbitrários se equipara aos referentes (objetos, acontecimentos, conceitos) e tem para o aprendiz o significado, seja ele qual for, que os referentes possuem. A aprendizagem conceitual é uma extensão da representacional e ocorre quando há formação e assimilação de conceitos, possuindo fases sucessivas de aperfeiçoamento. A aprendizagem proposicional é aquela que necessita do conhecimento prévio (de conceitos e símbolos) para atingir a compreensão sobre uma proposição.

Moreira; Masini (2006) ratificam a teoria de Ausubel, na qual aquilo que o aluno já sabe é o fator isolado mais importante que influencia a aprendizagem. Assim, o conhecimento prévio é condicionante para a nova aprendizagem, ocorrendo uma interação entre o novo e o já existente, sendo ambos modificados. Dessa forma, Moreira (2012, p. 6) ressalta que "na aprendizagem significativa, o novo conhecimento nunca é internalizado de maneira literal porque no momento em que passa a ter significado para o aprendiz, entra em cena o componente idiossincrático da significação.” Esse componente é único, pessoal, de cada indivíduo.

Outra distinção importante feita por Ausubel (2003) está relacionada aprendizagem por recepção e aprendizagem pela descoberta, que são dois tipos de processos bastante diferentes. O autor destaca que a maioria da instrução na sala de aula está organizada nas linhas da aprendizagem por recepção. 


\begin{abstract}
A aprendizagem por recepção e a aprendizagem pela descoberta não só possuem basicamente uma natureza e processos essencialmente diferentes como também diferem no que toca aos próprios papéis principais no desenvolvimento intelectual e no funcionamento cognitivo. Essencialmente adquirisse grandes conjuntos de matérias na escola através de aprendizagem por recepção ao passo que os problemas cotidianos se resolvem através da aprendizagem pela descoberta (AUSUBEL, 2003, p. 49).
\end{abstract}

Tendo a aprendizagem significativa como referencial para uma educação que preconiza a participação ativa do aluno na EJA, há de se pensar no papel do professor que vá ao encontro desse postulado. Se levarmos em conta que o público da EJA possui peculiaridades próprias, a aprendizagem por descoberta é, sem dúvida, a mais adequada e que deve ser priorizada pelo professor.

A partir dessa constatação, reforça-se que é imprescindível pensar no aluno da EJA como um sujeito que possui conhecimentos prévios, saberes, experiências e que constrói seus conhecimentos a partir deles. Nesse contexto, Freire (2001, p. 65-66) destaca como um saber necessário à prática educativa "é o que fala do respeito devido à autonomia do ser do educando". A reflexão sobre quem é esse educando, quais as suas aspirações e expectativas devem ser consideradas de grande relevância, principalmente nessa modalidade, cujos alunos são jovens e adultos com histórias de vida diversas e que, em sua maioria, precisam encontrar sentido no ambiente escolar.

Tendo essa premissa, o professor deve fazer das experiências concretas dos alunos a base dos processos de aprendizagem. Essa prática, como aponta Sobreira (2001), é denominada pedagogia orientada no participante, na qual o aluno, assim como o professor, é sujeito-ativo do seu processo de aprendizagem, buscando a construção de significados, ou seja, a aprendizagem significativa. Portanto, quando o professor da EJA se propõe a trabalhar com metodologias ativas, deve-se buscar desenvolver a aprendizagem pela descoberta e evitar a aprendizagem por recepção, pois trazer proposições, problematizar os conteúdos são ações que representam um estímulo a mais para o aluno e oportunizam a aprendizagem significativa.

\title{
3 AS METODOLOGIAS ATIVAS E SUA INTERLOCUÇÃO COM A EJA
}

Considerando que o mundo se encontra em constante transformação, permeado pela revolução tecnológica, científica e mudanças sociais, a instituição escolar e o ensino, propriamente dito, precisam estar em consonância com essa nova realidade. Pensar em propostas pedagógicas mais adequadas às demandas atuais e às necessidades humanas e sociais, como a sustentabilidade, representam uma mudança de paradigma.

Assim, na realidade atual, a discussão de tendências mais adequadas e apropriadas aos processos de ensino e aprendizagem se apresenta de extrema relevância, pois a prática da sala de aula ainda é marcada, em sua maioria, pela passividade do aluno e por metodologias aristotélicas. Nesse sentido, as metodologias ativas se apresentam como uma possível mudança, por meio de estratégias de ensino, que buscam garantir uma maior participação do aluno em sala de aula, destacando a sua liderança no seu processo de aprendizagem, tendo o professor como mediador desse processo. Moran (2018, p. 5) ressalta que "o papel principal do especialista ou docente é o de orientador, tutor dos estudantes individualmente ou nas atividades em grupo, nas quais os alunos são sempre protagonistas".

Segundo Gemignani (2012, p. 14), esse protagonismo do aluno "implica em uma nova visão sobre o ensino e a aprendizagem e representa o deslocamento do foco da dialética para o dialógico, para uma mudança da prática docente, voltada à sensibilização e à conscientização do sujeito para esta transformação". Nessa perspectiva, é importante pensar no sujeito que 
aprende como um educando que possui conhecimentos prévios, saberes e experiências. E quando a referência é a EJA, essa realidade se apresenta de maneira ainda mais marcante, pois este sujeito já possui uma história de vida, que ao serem valorizadas em sala de aula oportunizam seu protagonismo na aprendizagem, contribuindo para a sua permanência e o seu interesse pelos estudos.

Nesse contexto, as metodologias ativas são caracterizadas como metodologias alternativas ao ensino tradicional porque apresentam uma abordagem diferenciada de apresentação e desenvolvimento do trabalho pedagógico em sala de aula. Contudo, para classificar uma metodologia como viável ao processo de ensino e aprendizagem, é necessário estudar mais a fundo como o aluno aprende, conhecer esse universo e, assim, atender a essas expectativas, que podem ser alcançadas aprofundando o estuda das teorias de aprendizagem.

Nesse caso, elege-se para esse contexto reflexivo uma parceria das metodologias ativas com o embasamento teórico da aprendizagem significativa, pois acredita-se que o ensino deve culminar com a aprendizagem significativa dos alunos, sujeitos de suas aprendizagens. Essa abordagem vai ao encontro de uma perspectiva transformadora da realidade na qual, segundo Gemignani (2012, p. 3), "a complexidade dos problemas atuais exige novas competências, além do conhecimento específico, tais como: colaboração, conhecimento interdisciplinar, habilidade para a inovação, trabalho em grupo, educação para o desenvolvimento sustentável, regional e globalizado." Ou seja, uma concepção na qual as questões sociais, culturais, éticas, econômicas, ambientais, políticas são problematizadas para uma tomada de decisão participativa e responsável. Nesse sentido, Auler (2011, p. 93-94) "aponta para a educação, particularmente uma educação em ciências, que contribua para a constituição de valores democráticos e sustentáveis". O autor (apud Auler 2002, p. 76) se aproxima da proposta freireana quando "defende a necessidade da problematização de construções historicamente realizadas sobre a atividade científico-tecnológica [...]"; uma proposta de educação libertadora, transformadora, emancipatória, na qual a criticidade se faz necessária, quando se reflete sobre a realidade vivida, não havendo espaço para a neutralidade.

Portanto, acredita-se que as metodologias ativas se constituem como opção para uma educação coerente com essa conjuntura. Pode-se exemplificar, de acordo com Rocha e Lemos (2014), como pertencentes a essas metodologias: Aprendizagem Baseada em Problemas, Aprendizagem Baseada em Projetos, Instruções por pares (Peer Instruction), Ensino sob medida (Just-In-Time Teaching), Aprendizagem Baseada em Times, Método de Caso, Simulações. Greca; Villagrá (2018) destacam o Ensino por investigação. Todas essas metodologias possuem o objetivo comum de proporcionar uma aprendizagem contextualizada ao aluno, por meio de uma construção do conhecimento.

O ensino por investigação, considerado uma metodologia ativa, de acordo com Greca; Villagrá (2018), representa uma opção relevante quando se pretende romper a lógica disciplinar e reconhecer as áreas de conhecimento como integradas; propõe abordagens didáticas em que o aluno trabalhe colaborativamente ou cooperativamente enfrentando problemas, desenvolvendo projetos ou respondendo a questões de seu interesse ou coletivo, após fases ou estágios relativamente flexíveis, guiados ou orientados pelo professor.

Essa metodologia didática surge para ser usada, principalmente, no ensino de disciplinas científicas, para ampliar o conhecimento científico dos alunos, promovendo não apenas o conhecimento da ciência, mas também ofazer ciência e o conhecimento sobre ciência. Assim, as atividades de investigação científica buscam desenvolver nos alunos habilidades para formular perguntas e encontrar formas de coletar dados, por meio de observação e medição para respondê-las, analisar e interpretar dados e participar da discussão dos resultados e o processo para alcançá-los; sendo uma metodologia que leva ao conhecimento e compreensão do mundo natural e artificial (GRECA; VILLAGRÁ, 2018). 
Nessa perspectiva, Morin (2008, p. 21) ressalta que "a primeira finalidade do ensino foi formulada por Montaigne: mais vale uma cabeça bem-feita que bem cheia". Assim, ao invés de acumular o saber, o mais importante é dispor, ao mesmo tempo, de uma aptidão para colocar e tratar os problemas e princípios organizadores que permitam ligar os saberes e lhes dar sentido. Dessa forma, o que se objetiva é a construção do conhecimento e não apenas a sua memorização, alcançando, assim, a aprendizagem significativa.

Portanto, as metodologias ativas corroboram para se alcançar a aprendizagem significativa, especialmente na EJA, na medida em que colocam o sujeito como atuante e no centro do processo de aprendizagem, representando uma oportunidade de trabalho diferenciado para o professor de ciências.

Segundo Cachapuz et al. (2001), a didática das ciências na formação de professores deve ser vista como uma disciplina de caráter investigativo, sendo capaz de articular a teoria e a prática, a cultura da investigação e a cultura da ação.

Tardif (2002) destaca que o trabalho dos professores de profissão ${ }^{3}$ deve ser considerado como um espaço prático e específico de produção, de transformação e de mobilização de saberes e, portanto, de teorias, de conhecimentos e do saber-fazer, específicos do trabalho docente. Portanto, o professor de ciências que busca a aprendizagem significativa de seus alunos da EJA deve primar pela seleção e planejamento de conteúdos, estratégias e metodologias que sejam coerentes com esse pressuposto.

\section{O ENSINO DE CIÊNCIAS NA EDUCAÇÃO DE JOVENS E ADULTOS}

Ao fazer uma retrospectiva histórica, se percebe uma evolução no ensino de ciências, ao longo dos anos, sendo permeado por diversos movimentos, que refletem diferentes objetivos da educação, modificados em função de transformações no âmbito da política e economia nacional e mundial. Porém, esse processo tem sido marcado por avanços e retrocessos, erros e acertos, no qual o que se busca é atender aos objetivos de cada sociedade, bem como às necessidades do momento.

Nesse sentido, à medida que a ciência e a tecnologia foram evoluindo e se tornando essenciais para o desenvolvimento econômico, cultural e social das nações, o ensino das Ciências também foi crescendo de importância em diversos níveis.

Alguns autores, como Krasilchik (2000), Cachapuz (2005), Santos (2007), destacam que vários estudos mostraram a necessidade de uma reavaliação crítica do ensino de ciências nas escolas. Nesse sentido, é preciso que ocorram alterações profundas no papel da escola e reformulações curriculares, especialmente nas disciplinas científicas.

Krasilchik (2000) pontua a incoerência entre o disposto nas reformas educacionais, especialmente no ensino das ciências, e a realidade. A autora enfatiza que os resultados das pesquisas nessa área ainda não atingiram os centros de decisão, o que ocasiona falhas na preparação e avaliação dos currículos, nos projetos de aperfeiçoamento dos docentes e nas relações entre os elementos que interagem nas escolas.

Cachapuz et al. (2005, p. 39) ressalta que a forma como o ensino vem sendo implementado, transmite uma percepção equivocada da ciência e dos conhecimentos científicos, "visões empobrecidas e distorcidas que criam o desinteresse, quando não a rejeição, de muitos estudantes e se convertem num obstáculo para a aprendizagem”.

\footnotetext{
${ }^{3}$ Denominação dada pelo próprio autor aos professores de Ensino Fundamental e Médio. O autor argumenta que se deve levar em conta o conhecimento do trabalho dos professores, seus saberes cotidianos. Tal postura desconstrói a ideia tradicional de que os professores são apenas transmissores de saberes produzidos por outros grupos. Sua proposta é que a pesquisa universitária pare de ver os professores de profissão como objetos de pesquisa e que passem a ser considerados como sujeitos do conhecimento, como colaboradores, como copesquisadores.
} 
Nesse contexto, há que se refletir, ainda, sobre o trabalho experimental no ensino de ciências, pois a experimentação desperta um forte interesse nos alunos, devido ao seu caráter lúdico e interativo, essencialmente vinculado aos sentidos. Porém, é necessário superar a concepção de simples prática de laboratório em situações de ensino, sustentada pela aplicação do Método Científico, de influência positivista. Bachelard (apud Giordan, 1999, p. 46) destaca o papel do erro no progresso da ciência, rompendo como a linearidade da sucessão "fenômeno corretamente observado/medido $\rightarrow$ interpretação inequívoca", destacando que essa concepção obstrui o pensamento reflexivo e corrobora as explicações imediatas. Dessa forma, a experimentação coerente com uma proposta pedagógica que promova aprendizagem significativa deve permitir as possibilidades de erro e acerto, utilizando-os como estratégia de ensino.

Nessa conjuntura, a democratização do ensino de ciências ainda é necessária, principalmente quando nos referimos à modalidade EJA. É preciso um bom ensino de ciências para todos e que seja desmistificada a ideia de que a ciência está à disposição de apenas alguns privilegiados. Essa premissa necessita ser priorizada, principalmente quando se acredita no papel da educação como mecanismo de inclusão social.

Assim, o ensino de ciências na EJA representa uma oportunidade de desenvolvimento da chamada alfabetização ou letramento científico, de acordo com Chassot (2003), contribuindo para a inclusão desses sujeitos e com a popularização da ciência. Nesse contexto, os conhecimentos científicos e tecnológicos devem instrumentalizar os alunos para atuarem como cidadãos, participando do desenvolvimento da humanidade. Chassot (2003, p. 91) acrescenta a ideia de que a ciência seja encarada como uma linguagem. Assim, para ele, "ser alfabetizado cientificamente é saber ler a linguagem em que está escrita a natureza." Essa leitura do mundo natural, segundo ele, nos ajuda a entender o mundo em que vivemos, como também contribui para a inclusão social, sendo "facilitadora do estar fazendo parte do mundo" (CHASSOT, 2003, p. 93).

Santos (2007, p. 478) ressalta que "os grandes domínios da educação científica estão centrados na compreensão do conteúdo científico e na compreensão da função social da ciência [...], estando estes interrelacionados e imbricados". De acordo com o autor, não se pode pensar a educação científica de forma neutra; como também não é possível questionar a função social do conhecimento científico, sem a compreensão do seu conteúdo.

Mais recentemente, Lederman et al. (2018) realizaram uma pesquisa colaborativa em vários países do mundo, incluindo o Brasil, para avaliar como a investigação científica é compreendida por alunos do ensino fundamental. Ao analisar as respostas dos estudantes brasileiros, percebeu-se que eles podem conceituar alguns aspectos da investigação científica, mas não conseguem identificá-los em situações reais. Esse resultado reflete a falta de ênfase curricular nacional sobre a investigação científica no ensino de ciências do ensino fundamental e a ausência de experiência em investigar nas salas de aula de ciências. Esse resultado não foi muito diferente dos demais países participantes da pesquisa, pois, de um modo geral, os resultados mostraram, predominantemente, que estudantes no segundo segmento do ensino fundamental têm muito pouco entendimento sobre o que é investigação científica, apesar de ser considerado um objetivo altamente valorizado da educação científica em todo o mundo e de ser um componente significativo da alfabetização científica.

Nessa perspectiva, percebe-se que os currículos escolares ainda precisam superar a fragmentação e especialização do saber científico.

Tornar a educação científica uma cultura científica é desenvolver valores estéticos e de sensibilidade, popularizando o conhecimento científico pelo seu uso social como modos elaborados de resolver problemas humanos. Para isso, torna-se relevante o uso de meios informais de divulgação científica, como textos de jornais e revistas e programas televisivos e radiofônicos em sala de aula. Além disso, visitas programadas 
a espaços não-formais de educação, como museus de ciência, jardins zoológicos, jardins botânicos, planetários, centros de visita de instituições de pesquisa e de parques de proteção ambiental e museus virtuais, entre outros, são importantes estratégias para inculcar valores da ciência na prática social (SANTOS, 2007, p. 487).

O desenvolvimento dessa cultura científica é extremamente relevante na Educação de jovens e adultos, já que estes sujeitos têm acesso a muitos desses meios de comunicação e também podem comparecer, de forma independente, a espaços não-formais, desde que sejam incentivados, tenham interesse e/ou percebam sua importância.

Porém, apesar de estarmos no século XXI, ainda existe a necessidade de se superar o cientificismo, ou seja, a supervalorização do conhecimento científico em detrimento às demais áreas do conhecimento humano. Como destacado por Santos (1991), a crise do paradigma dominante se apresenta como sendo, não só profunda, como também irreversível, visto que o paradigma vigente não dá mais conta das complexidades de nossa realidade. A visão holística e transdisciplinar do paradigma emergente supera uma visão fragmentada e disciplinar. Nessa perspectiva, é mister perceber o ser humano como um ser complexo, inserido numa sociedade em constante transformação, bem como repensar as funções da escola e planejar um ensino mais adequado e coerente com os objetivos dos alunos para o qual essa educação se destina.

Nesse contexto, a interdisciplinaridade e a contextualização devem ser priorizadas na elaboração do currículo escolar na EJA, favorecendo uma maior interlocução entre os conteúdos trabalhados e a realidade dos alunos. Em se tratando do ensino das Ciências, essa prática se torna extremamente relevante, pois as disciplinas científicas estão intimamente relacionadas e, planejadas adequadamente, despertam o interesse do aluno e a sua participação mais efetiva. Assim, no que tange à EJA, a interdisciplinaridade e a contextualização representam uma oportunidade de se obter uma aprendizagem significativa. A interdisciplinaridade leva o alunado a perceber a inter-relação entre os conteúdos curriculares, rompendo com a divisão das disciplinas; a busca pela contextualização é realizada quando se trabalha com questões atuais, da vivência dos alunos. Ao trazer para a sala de aula a realidade vivida pelos alunos, estes se sentem mais motivados e participam das aulas com mais empenho. Essa atitude aumenta a autoestima dos alunos e contribui para uma melhor aprendizagem, o que na EJA é de extrema relevância.

É importante destacar, ainda, uma prática que, cada vez mais, tem sido incorporada ao ensino de ciências: a aprendizagem colaborativa.

\footnotetext{
É necessário criar oportunidades não somente para realizar experimentos em equipe, mas também para a colaboração entre equipes. A formação de um espírito colaborativo de equipe pressupõe uma contextualização socialmente significativa para a aprendizagem, tanto do ponto de vista da problematização - temas socialmente relevantes, como também da organização do conhecimento científico - temas epistemologicamente significativos (GIORDAN, 1999, p. 6).
}

Quando o processo de ensino de ciências é desenvolvido nessa perspectiva, o professor caminha para a promoção de uma aprendizagem significativa, promovendo a interação entre os alunos, a troca de experiências, contextualizando e dando sentido ao conhecimento.

Portanto, deve-se estimular no ensino de ciências da EJA a prática em sala de aula de desenvolver o processo educativo, a partir de concepções prévias dos alunos e seus contextos, oportunizando que os saberes desses jovens e adultos sejam compartilhados e valorizados. Esses saberes, muitas vezes, acabam sendo desmistificados e, outras vezes, ratificados por fazerem parte da cultura popular.

Segundo Pozo (1998), para a inserção de um novo assunto, a utilização de técnicas, como: entrevistas, questionários e situações-problemas devem levar o professor a conhecer as concepções alternativas (ou concepções prévias) dos alunos, auxiliando-o no seu planejamento; 
bem como oportunizar espaços para que os alunos manifestem suas concepções alternativas e propiciar discussões que favoreçam a integração de ideias, concepções e o trabalho colaborativo.

\begin{abstract}
Independente da estratégia adotada, para verificar qual o nível de conhecimento que os alunos trazem para a sala de aula, o professor deverá elaborar um roteiro de atividades, por meio da inserção de um problema que faz parte do cotidiano do aluno. Este problema deverá abordar indiretamente os aspectos mais importantes sobre o conteúdo e, ao mesmo tempo, fazer com que o conteúdo seja compatível com o grau de conhecimento em que o aluno se encontra (OLIVEIRA, 2005, p. 239).
\end{abstract}

Cabe destacar, outra questão relevante apontada por Moran $(2018$, p. 9) "a combinação de aprendizagens personalizadas, grupais e tutoriais no projeto pedagógico é poderosa para obter os resultados desejados". Nesse contexto, fica evidente a importância do papel do professor no planejamento e organização das atividades de ensino na EJA e, consequentemente, a formação do mesmo frente à essa realidade. Se ao professor é atribuído o papel de organizador do processo ensino aprendizagem, interlocutor entre os alunos e o conhecimento, sua formação deve ser permeada pela reflexão, ou seja, pelo repensar contínuo do ser e fazer pedagógico, de forma crítica, humana e responsável, buscando a parceria com seus pares e o desejo permanente de fazer a diferença na vida dos alunos.

É digna de nota a capacidade que tem a experiência pedagógica para despertar, estimular e desenvolver em nós o gosto de querer bem e o gosto da alegria sem a qual a prática educativa perde o sentido. É esta força misteriosa, às vezes chamada vocação, que explica a quase devoção com que a grande maioria do magistério nele permanece, apesar da imoralidade dos salários. E não apenas permanece, mas cumpre, como pode, seu dever. Amorosamente [...] (FREIRE, 2001, p. 161).

Nessa perspectiva, é necessário competência técnica e sensibilidade para poder intervir de forma consciente e planejada, visando a melhoria da qualidade do processo educativo e atendendo as demandas apresentadas pelos alunos da EJA.

Portanto, o uso de metodologias ativas no ensino de ciências, adequado à realidade dessa modalidade de ensino, se apresenta como estratégia eficaz para aprendizagem significativa desses sujeitos da EJA, favorecendo uma formação humana e educacional, coerente com seus anseios e suas reais necessidades.

\title{
5 CONSIDERAÇÕES FINAIS
}

Este artigo não tem a pretensão de esgotar o assunto, e sim apresentar algumas reflexões sobre como a educação de jovens e adultos pode ser ressignificada, na busca de uma participação ativa do aluno, para que ele se torne protagonista e sujeito de sua aprendizagem.

Repensar e reconstruir permanentemente a prática pedagógica é primordial no exercício docente, especialmente na EJA, uma modalidade de ensino que possui uma especificidade em relação aos seus sujeitos: jovens e adultos que já possuem as marcas da exclusão social. Assim, o professor da EJA deve promover um ambiente acolhedor em sala de aula, no qual o aluno se sinta pertencente àquele espaço educativo.

As metodologias ativas são vistas como uma oportunidade de desenvolver nos alunos da EJA, um conjunto de habilidades de pensamento, raciocínio, trabalho em equipe, pesquisa, comunicação e criatividade, de modo que possam usar essas habilidades em todas as áreas em que atuarem. Nesse sentido, implementar o ensino de ciências a partir de metodologias ativas e priorizar a aprendizagem significativa representam um compromisso com esses sujeitos e com as demandas emergentes do mundo atual. 
É necessário reorientar as estratégias educativas, em busca de um novo modelo de aprendizagem das ciências, mediante um processo de investigação científica, que leve a reconstrução de conhecimentos e que pode ser alcançado, a partir de situações problemáticas de interesse dos alunos.

Romper com a abordagem disciplinar do currículo e propor um currículo integrado, exige uma formação adequada dos professores e o desenvolvimento de novos recursos de ensino (livros, materiais, software etc.).

O magistério exige comprometimento, estudo, questionamento, reflexão e pesquisa. Assim, a formação do professor deve ser realizada numa perspectiva técnica (não alienada), prática e crítica, emancipatória, na qual se busque respostas para as indagações e necessidades reais dos alunos e da sociedade.

Assim, pensar em aprendizagem significativa no ensino de ciências na EJA representa almejar um ensino significativo, em uma escola que faça sentido para o aluno trabalhador e para a sociedade; concebida como um organismo vivo, em constante desenvolvimento, norteada pelo objetivo maior de educar, que se concretiza através de um projeto educativo crítico.

As reflexões aqui apresentadas não representam apenas um discurso inovador, mas uma concepção de aprendizagem e proposta de metodologias adequadas ao contexto atual; e que, de fato, colocam o aluno da EJA como sujeito protagonista do ato educativo; sujeito este capaz de colaborar para as transformações que a sociedade tanto necessita. É papel da educação contribuir para um país e um mundo melhor, em que a tolerância, a igualdade, a justiça social e o respeito pelos outros constituam valores humanos imprescindíveis.

\section{REFERÊNCIAS}

ALARCÃO, Isabel. Professores reflexivos em escola reflexiva. São Paulo: Cortez, 2003.

AULER, Décio; SANTOS, Widson Luiz Pereira dos. CTS e educação científica: desafios, tendências e resultados de pesquisa. Brasília: Editora UnB, 2011.

AUSUBEL, David Paul. Aquisição e retenção de conhecimentos: uma perspectiva cognitiva. Tradução Lígia Teopisto. 1. ed. Lisboa: Paralelo Editora, 2003, 226 p. Título original: The acquisition and retention of knowledge: a cognitive view. ISBN 972-707-364-6

BRASIL. Parecer CNE/CEB n ${ }^{\circ} 11 / 00$. Diretrizes Curriculares Nacionais para a Educação de Jovens e Adultos. Brasília: MEC, 2000.

CACHAPUZ, António; CARRASCOSA ALÍS, Jaime; GIL-PÉREZ, Daniel; TERRADES, Isabel Martinéz . A emergência da didática das ciências como campo específico de conhecimento. Revista Portuguesa de Educação, Minho, v. 14, n. 1, p. 155-95, 2001. Disponível em:

https:www.researchgate.net/publication/26464941_A_emergencia_da_didactica_das_ciencias _como_campo_especifico_de_conhecimento. Acesso em: 29 set. 2020.

CACHAPUZ, António; CARVALHO, Ana Maria Pessoa de; GIL-PEREZ, Daniel; PRAIA, João.; VILCHES, Amparo (Org.) A necessária revolução do ensino de ciências. São Paulo: Cortez, 2005.

CHASSOT, Áttico. Alfabetização científica: uma possibilidade para a inclusão social. Revista Brasileira de Educação, ANPEd, n. 26, p.89-100, 2003. Disponível em: 
https:www.scielo.br/scielo.php?pid=S1413-

$24782003000100009 \&$ script=sci_abstract\&tlng=pt. Acesso em: 27 set.2020.

FÁVERO, Osmar. Materiais didáticos para a educação de jovens e adultos. Cadernos Cedes, Campinas, v. 27, n. 71, p. 39-62, 2007. Disponível em:

https:www.scielo.br/pdf/ccedes/v27n71/a04v2771.pdf. Acesso em: 27 set.2020

FREIRE, Paulo. Educação e Mudança. São Paulo: Paz e Terra, 2007.

FREIRE, Paulo. Pedagogia da Autonomia. São Paulo: Paz e Terra, 2001.

GEMIGNANI, Elizabeth Yu Me Yut. Formação e professores e metodologias ativas de ensino -aprendizagem: ensinar para a compreensão. Revista Fronteiras da educação. Recife, v.1, n. 2, 2012. Disponível em:

http:www.fronteirasdaeducacao.org/index.php/fronteiras/article/view/14. Acesso em: 22 maio 2019.

GIORDAN, Marcelo. O papel da experimentação no ensino de ciências. Química Nova na Escola, São Paulo, n. 10, p. 43-49, Nov. 1999. Disponível em:

http:qnesc.sbq.org.br/online/qnesc10/pesquisa.pdf. Acesso em: 27 set. 2020

GRECA, Ileana M.; VILLAGRÁ, Jesús Ángel Meneses. (Coords.) STEAM en Educación Primaria: aplicaciones prácticas. Madrid: Dextra Editorial, 2018.

KRASILCHIK, Myriam. Reformas e realidade: o caso do ensino das ciências. São Paulo em Perspectivas, São Paulo, v. 14, n. 1, p. 85-93, 2000. Disponível em:

https:www.scielo.br/scielo.php?script=sci_arttext\&pid=S0102-88392000000100010. Acesso em: 28 set. 2020

LEDERMAN, Judith; LEDERMAN Norman; BARTELS, Selina; JIMENEZ Juan. An international collaborative investigation of beginning seventh grade students' understandings of scientific inquiry: establishing a baseline. J Res Sci Teach, p. 1-30, 2019. Disponível em: https:doi.org/10.1002/tea. 21512. Acesso em: 02 fev 2020.

MORAN, José. Metodologias ativas para uma aprendizagem mais profunda. In: BACICH, Lilian.; MORAN, José. (org.) Metodologias ativas para uma educação inovadora. Porto Alegre: Penso, 2018, p. 2-25.

MOREIRA, Marco Antonio; MASINI, Elcie F. Salzano. Aprendizagem significativa: a teoria de aprendizagem de David Ausubel. 2 ed. São Paulo: Centauro Editora, 2006.

MOREIRA, Marco Antonio. Mapas conceituais e Aprendizagem significativa. Revista Chilena de Educação Científica, v. 4, n. 2, 2005 p. 38-44. (Revisado em 2012). Disponível em http:www.if.ufrgs.br/ moreira/mapasport.pdf. Acesso em: 29 set. 2020.

MORIN, Edgar. A cabeça bem-feita: repensa a reforma, reformar o pensamento. Rio de Janeiro: Bertrand Brasil, 15 ed. 2008. 
OLIVEIRA, Inês Barbosa. Reflexões acerca da organização curricular e das práticas pedagógicas da EJA. Educar, Curitiba, n. 29, p. 83-100, 2007. Disponível em: https:www.scielo.br/pdf/er/n29/07.pdf. Acesso em: 28 set. 2020.

OLIVIERA, Marta Kohl de. Jovens e adultos como sujeitos de conhecimento e aprendizagem. Revista Brasileira de Educação, Rio de Janeiro, p.59-73, set. 1999.

OLIVEIRA, Silmara Sartoreto. Concepções alternativas e ensino de biologia: como utilizar estratégias diferenciadas na formação inicial de licenciados. Educar, Curitiba, n. 26, p. 233250, 2005. Disponível em: https:www.scielo.br/pdf/er/n26/n26a16.pdf. Acesso em: 28 set. 2020.

POZO, Juan Ignácio. A aprendizagem e o ensino de fatos e conceitos. In: COLL, Cesar. et al. Os conteúdos na reforma. Porto Alegre: Artes médicas, 1998. p. 17-71.

ROCHA, Henrique Martins; LEMOS, Washington Macedo. Metodologias ativas: do que estamos falando? Base conceitual e relato de pesquisa em andamento. IX Simpósio Pedagógico e Pesquisas em Educação, 2014. Disponível em: https:www.aedb.br/wpcontent/uploads/2015/05/41321569.pdf. Acesso em: 29 set. 2020.

SANTOS, Boaventura Souza. Um discurso sobre as Ciências. Porto Alegre: Melhoramentos, 1991.

SANTOS, Wildson. Luiz. Pereira dos. Educação científica na perspectiva de letramento como prática social: funções, princípios e desafios. Revista Brasileira de Educação, ANPED, Rio de Janeiro, v. 12, n.36, p. 474-550, 2007. Disponível em:

https:www.scielo.br/pdf/rbedu/v12n36/a07v1236.pdf. Acesso em: 28 set.2020.

SILVA, Janssen Felipe da. Avaliação do ensino e da aprendizagem numa perspectiva formativa reguladora. In: ESTEBAN, Maria Teresa.; HOFFMANN, Jussara; SILVA, Janssen Felipe da. (org.) Práticas avaliativas e aprendizagens significativas em diferentes áreas do currículo. Porto Alegre: Mediação, 2003, p. 7-18.

SOBREIRA, Henrique Garcia. Anotações éticas e estéticas sobre a educação do educador. In: RAMOS-DE-OLIVEIRA, Newton; ZUIN, Antônio Álvaro Soares; PUCCI, Bruno. (Org.) Teoria crítica, estética e educação. Campinas: Autores associados, Unimep, 2001, p. 16175 .

SOUZA, Marta Lima de. Alfabetização e aprendizagem ao longo da vida: armadilhas e refúgios. In: SOUZA, José Santos.; SALES, Sandra Regina. (Org.) Educação de Jovens e Adultos: políticas e práticas educativas. Rio de Janeiro: NAU Editora, 2011.

TARDIF, Maurice. Saberes docentes e formação profissional. Petrópolis: Vozes, 2002. 